\title{
Uso de cal virgem para o controle de Salmonella spp. e Clostridium spp. em camas de aviário
}

\author{
Quicklime for controlling Salmonella spp. and Clostridium spp in litter from floor pens of broilers
}

\author{
Marcos Antonio Dai Pra' Érico Kunde CorrêaII Victor Fernando Roll ${ }^{\mathrm{II}}$ Eduardo Gonçalves Xavier ${ }^{\mathrm{III}}$ \\ Débora Cristina Nichelle Lopes ${ }^{\mathrm{III}}$ Fernanda Fernandes Lourenço ${ }^{\mathrm{III}}$ Jerri Teixeira Zanusso ${ }^{\mathrm{III}}$ \\ Aline Piccini Roll'II
}

\section{RESUMO}

O objetivo deste trabalho foi avaliar a eficácia do uso de cal virgem (CaO) para a redução de Salmonella spp. e Clostridium spp. em cama de aviário. Foram aplicados quatro tratamentos: T1- sem adição de cal virgem (controle), T2aplicação de cal virgem na dose de $300 \mathrm{~g} \mathrm{~m}^{-2}$, T3- aplicação de cal virgem na dose de $600 \mathrm{~g} \mathrm{~m}^{-2}$ e T4- aplicação de cal virgem na dose de $900 \mathrm{~g} \mathrm{~m}^{-2}$. Os valores médios observados para o $\mathrm{pH}$ da cama após o $12^{\circ}$ dia de aplicação de cal virgem foram 8,95 e 9,91, 10,75 e 11,11 para os tratamentos 1, 2, 3 e 4, respectivamente. O número mais provável $\log _{10}(U F C)$ de Salmonella spp. e Clostridium spp foi reduzido em 82 e $97 \%$ com a aplicação de cal na dosagem de $300 \mathrm{~g} \mathrm{~m}^{-2}$ e $100 \%$ na dosagem de 600 e $900 \mathrm{~g} \mathrm{~m}^{-2}$, ambos diferindo significativamente em relação ao controle (antes da aplicação da cal). A atividade de água da cama reduziu progressivamente (de 0,2 a 3,82\%) com a utilização de níveis crescentes de cal. Conclui-se que o uso da cal na cama de aviário, mesmo nas doses mais baixas, reduz o número mais provável de Salmonella e Clostridium ssp.

Palavras-chave: bactérias, eficácia, redução, atividade de água.

\section{ABSTRACT}

This study aimed to evaluate the efficacy of quicklime (CaO) for reducing Salmonella and Clostridium spp. population in used litter from floor pens of broilers. Four treatments were tested: (T1) control (without quicklime); (T2) $300 \mathrm{~g}$ quicklime $\mathrm{m}^{-2}$; (T3) $600 \mathrm{~g}$ quicklime $\mathrm{m}^{-2}$; and (T4) $900 \mathrm{~g}$ quicklime $\mathrm{m}^{-2}$. The following average $\mathrm{pH}$ values were observed
12 days after adding quicklime: 8.95, 9.91, 10.75 and 11.11 for treatments 1, 2, 3 and 4, respectively. An 82 and $97 \%$ reduction in the most probable number $\log _{10}$ (CFU) of Salmonella and Clostridium spp, respectively, was observed when $300 \mathrm{~g} \mathrm{~m}^{-2}$ of quicklime was added to the used litter from floor pens of broilers. Additionally, a 100\% reduction was obtained when both 600 and $900 \mathrm{~g} \mathrm{~m}^{-2}$ of quicklime were added, differing significantly from control (before adding quicklime). A progressive reduction in water activity (from 0.2 to $3.82 \%$ ) was observed when growing levels of quicklime were used. In conclusion, even the lowest level of quicklime added to litter from floor pens of broilers reduces the most probable number of Salmonella and Clostridium spp

Key words: bacteria, efficacy, reduction, water activity.

\section{INTRODUÇÃO}

Devido ao elevado número de aviários no Brasil, a demanda por materiais utilizados como cama é grande, acarretando a difusão de práticas de manejo específicas, como o aumento do número de lotes sobre a mesma cama. Esse fator pode contribuir para a presença de microrganismos, como Salmonella spp. no ambiente de produção (CHERNAKI-LEFFER, 2002).

Dentre as bactérias, as do gênero Salmonella spp. apresentam maior importância na avicultura por representarem risco de contaminação

IEmpresa Perdigão S.A. Av Presidente Vargas, 1040, 99150 000, Marau, RS, Brasil. E-mail: mrr@perdigao.com.br. Autor para correspondência.

"Centro Federal de Educação Tecnológica de Bento Gonçalves (CEFETBG), Unidade de Ensino Descentralizada (UNED), Santo Augusto, RS, Brasil.

II'Departamento de Zootecnia, Faculdade de Agronomia Eliseu Maciel (FAEM), Universidade Federal de Pelotas (UFPel). Pelotas, RS, Brasil. 
alimentar em seres humanos, uma vez que geralmente as pessoas são infectadas pelo consumo ou contato com alimentos contaminados.

As salmoneloses aviárias podem ter como agente causal, dentre outros, a Salmonella enteritidis e $\boldsymbol{S}$. typhimurium, as quais são classificadas em patologia aviária como salmonelas paratíficas, ou seja, provocam doenças agudas ou crônicas em aves e muitos outros animais (CORRIER et al., 1992; KWAK et al., 2005).

Outro importante fator envolvido na disseminação de Salmonella spp. e Clostridium spp. é a cama do aviário, que vem a ser uma cobertura de aproximadamente $5 \mathrm{~cm}$, disposta sobre o piso do galpão, feita a partir de materiais como raspas ou serragem de pinho, eucalipto, madeira de lei, casca de arroz, bagaço de cana, sabugo de milho ou palha (ÁVILA et al., 1992; OLIVEIRA et al., 2003). A cama de aviário pode ser renovada a cada ciclo de produção ou reutilizada entre quatro e seis lotes de frangos, quando cada lote fica alojado por aproximadamente 45 dias, assim, de modo geral, a densidade situa-se entre 12 e 15 aves por $\mathrm{m}^{2} \mathrm{de}$ aviário (FERREIRA et al., 2004). A transmissão de Salmonella spp. para as aves pode ocorrer de forma vertical, via ovo, desencadeando o nascimento de pintos infectados, ou horizontal, com a ingestão de água, ração, cama, matéria fecal ou poeira contaminada. As barreiras sanitárias, o monitoramento dos lotes e os princípios de biosseguridade, em conjunto com os métodos atualmente empregados, não bastam para garantir que um lote esteja livre da ocorrência de um surto de salmonelas. Dentre os métodos utilizados durante o vazio sanitário, emprega-se o tratamento da cama de aviário com ácidos orgânicos, o uso da revira associada com amontoamento da cama e o uso da cal virgem (NASCIMENTO \& SANTOS, 2005).

A umidade da cama é um dos fatores determinantes para o aumento da temperatura e da proliferação microbiana, com fermentação e liberação de gases, como nitritos, nitratos, amônia e sulfato de hidrogênio (McWARD \& TAYLOR, 2000). O equilíbrio dinâmico dos microrganismos depende da sua capacidade de adaptação ao meio, o que determinará sua maior ou menor competitividade (CORRÊA et al., 2000).

A cama deve ter uma taxa de umidade que não gere poeira em excesso, nem retenha muito a umidade, de forma que dificulte a proliferação de microrganismos. Uma cama com $22 \%$ de umidade não apresenta Salmonella spp., Escherichia coli, Listeria, Campylobacter ou Staphylococcus spp. toxigênicos (FERREIRA et al., 2004). A serragem úmida ou a presença de resíduos de grãos (milho, amendoim e arroz) na cama é de elevado risco para a presença de esporos e conídios de fungos patogênicos, bem como micotoxinas, cuja eliminação total é inviável (McWARD \& TAYLOR, 2000). Em estudo realizado por KWAK et al. (2005), foram encontrados 31 gêneros distintos de bactérias na cama aviária, sendo $82 \%$ gram-positivas, principalmente Lactobacillus $s p$ e Salinococcus $s p$ e alguns Clostridium $s p$, Staphylococcus $s p$ e Bordetella sp.

Existem substâncias que, quando adicionadas à cama de frango, atuam como condicionadores. Em alguns trabalhos relatados na literatura, foi observada melhora na qualidade da cama por meio da diminuição do teor de umidade, redução da volatilização de amônia e alteração do $\mathrm{pH}$, quando esta recebeu a adição de gesso agrícola (PROCHONOW et al., 2001), bissulfeto de sódio (POPE \& CHERRY, 2000), sulfato de alumínio (MOORE et al., 1996) e cal apagada (SINGH et al., 1990). Por outro lado, FERREIRA et al. (2004) não observaram efeito sobre o desempenho de frangos de corte quando a cama sofreu adição de sulfato de alumínio, gesso agrícola, superfosfato simples e cal hidratada, quando comparados à cama não tratada. Isso evidencia uma divergência de resultados na literatura.

O efeito da adição dessas substâncias sobre a cama de frangos pode ser explicado pela sua ação sobre a biocomplexidade presente na cama, reduzindo a atividade, tanto de bactérias, quanto de fungos (FERREIRA et al., 2004). Como conseqüência da menor atividade microbiana, pode ocorrer uma redução da produção de amônia ou a diminuição de sua volatilização (McWARD \& TAYLOR, 2000).

Frangos de corte criados em cama tratada com sulfato de alumínio apresentaram maior ganho de peso (McWARD \& TAYLOR, 2000), melhor conversão alimentar (OLIVEIRA et al., 2003) e menor mortalidade (MOORE et al., 1996). Outros benefícios incluem menor gasto com ventilação e melhoria na qualidade da cama para ser usada como fertilizante (MOORE et al., 1996), além de melhoria na qualidade da carcaça, com menor incidência de lesões no peito, no coxim plantar e nos sacos aéreos (McWARD \& TAYLOR, 2000). Desse modo, o objetivo deste trabalho foi avaliar o efeito da adição de diferentes concentrações de cal virgem na cama avícola sobre a prevalência de Salmonella spp. e Clostridium spp.

\section{MATERIAL E MÉTODOS}

Foram utilizados quatro tratamentos: (T1) sem adição de cal (controle), (T2) aplicação de cal virgem na dose de $300 \mathrm{~g} \mathrm{~m}^{-2}$, (T3) aplicação de cal virgem na 
dose de $600 \mathrm{~g} \mathrm{~m}^{-2}$ e (T4) aplicação de cal virgem na dose de $900 \mathrm{~g} \mathrm{~m}^{-2}$. O experimento foi realizado em duas fases: a primeira foi realizada no Departamento de Zootecnia da Universidade Federal de Pelotas, e a segunda fase foi realizada em aviários de frango de corte de uma empresa integradora do Rio Grande do Sul.

$\mathrm{Na}$ primeira fase, a cama, anteriormente utilizada por um lote de aves, foi acondicionada em caixas de madeira com dimensões de $0,5 \mathrm{~m}$ de largura, $0,5 \mathrm{~m}$ de comprimento e $0,15 \mathrm{~m}$ de profundidade, utilizando-se $0,10 \mathrm{~m}$ de cama em cada caixa e obtendose volume final de cama por caixa de $0,025 \mathrm{~m}^{3}$. A primeira fase teve a duração de 12 dias, período que corresponde ao tempo médio de vazio sanitário utilizado na criação comercial de frangos de corte, e teve por objetivo medir a temperatura e o $\mathrm{pH}$ nos diferentes tratamentos. Para tal, foram utilizadas sete repetições por tratamento, e cada caixa foi considerada uma unidade experimental. Foram registrados, diariamente, o $\mathrm{pH}$ e a temperatura da cama. Para o $\mathrm{pH}$, foram usadas alíquotas de $10 \mathrm{~g}$ da amostra in natura, diluída em $50 \mathrm{~mL}$ de água destilada (TEDESCO et al., 1995), com a leitura em pHmetro digital, modelo 330i/SET, marca WTW. As temperaturas foram medidas com o uso de termômetro digital da marca INCOTERM, com precisão de $\pm 0,1^{\circ} \mathrm{C}$. A temperatura das camas foi tomada com sonda metálica, no centro e com meia profundidade.

$\mathrm{Na}$ segunda fase, foram utilizados 16 aviários de $1200 \mathrm{~m}^{2}$, com capacidade de alojamento para 15000 aves, divididos em grupos de quatro aviários por tratamento. A cama utilizada nos aviários tinha em média 12 a $15 \mathrm{~cm}$. A aplicação da cal ocorreu dois dias antes do alojamento dos pintos, sempre após a retirada das partes incrustadas da cama e a queima de penas do lote anterior.

Foram realizadas três coletas de amostras: a primeira antes da aplicação de cal (dois dias antes do alojamento), a segunda sete dias após o alojamento e a terceira coleta 28 dias após o alojamento. Foram coletadas amostras de cama em 30 pontos distribuídos ao longo do aviário e colocadas em recipiente onde foram homogeneizadas formando um pool. A partir desse volume, foram retiradas três amostras e colocadas em embalagem esterilizada, que posteriormente foram resfriadas e enviadas para o laboratório de patologia. Todas as amostras foram coletadas em triplicata. Em cada amostra foi realizada a determinação do número mais provável (NMP) de Salmonella spp. e Clostridium spp.

A quantificação de Salmonella spp. foi realizada por meio da técnica do número mais provável (NMP). A partir do pool de amostras de cada unidade experimental, retirou-se $25 \mathrm{~g}$ para compor a unidade analítica. À unidade analítica foram adicionados $225 \mathrm{~mL}$ de água peptonada tamponada (APT). Esse conjunto foi incubado a $37^{\circ} \mathrm{C}$ por $24 \mathrm{~h}$. Em seguida, foi realizada uma diluição decimal seriada, sendo obtidas as diluições $10^{0}, 10^{-1}, 10^{-2}, 10^{-3}$ e $10^{-4}$. De cada diluição, transferiu-se $1 \mathrm{~mL}$ para tubos contendo $10 \mathrm{~mL}$ de caldo Tetrationato (TT, Oxoid), em triplicata, os quais foram incubados a $37^{\circ} \mathrm{C}$ por $24 \mathrm{~h}$. De cada tubo de TT, os caldos foram inoculados em ágar XLT4, as quais foram incubadas a $37^{\circ} \mathrm{C}$ por $24 \mathrm{~h}$.

Para a quantificação de Clostridium spp., após as diluições $(100 \mu \mathrm{L})$, os caldos foram passadas para ágar SPS (específico para contagem de Clostridium sulfito redutores). As amostras foram submergidas em ágar fundido e, após solidificadas, foram incubadas a $37^{\circ}$ por $24 \mathrm{~h}$ para posterior leitura e contagem. Para avaliar a atividade de água, foi utilizado o equipamento AquaLab Series 3 e 3TE - DECAGON, BRASEQ, seguindo a metodologia descrita por PARDI et al. (2001).

O delineamento experimental utilizado foi o completamente casualizado. Os dados foram submetidos à análise de variância, e as médias dos tratamentos foram comparadas pelo teste de Fisher, exceto a variável atividade de água, que foi analisada por meio do teste " $t$ " pareado. O modelo estatístico adotado nas duas fases do experimento foi o seguinte: $\mathrm{Y}_{\mathrm{ij}}=\mathrm{m}+\mathrm{t}_{\mathrm{i}}+\mathrm{e}_{\mathrm{ij}}$. em que: $\mathrm{m}=$ média observada da variável resposta; $\mathrm{t}_{\mathrm{i}}=$ efeito do tratamento, $\mathrm{i}=1,2,3, \ldots . \mathrm{e}_{\mathrm{ij}}=$ erro experimental associado com a repetição $j(j=1,2,3, \ldots)$ no tratamento $\mathrm{i}$.

\section{RESULTADOS E DISCUSSÃO}

Os valores médios observados para $\mathrm{pH}$ da cama após o $12^{\circ}$ dia de administração de cal virgem foram $8,95,9,91,10,75$ e 11,11 para os tratamentos 1 $\left(0,0 \mathrm{~g} \mathrm{~m}^{-2}\right), 2\left(300 \mathrm{~g} \mathrm{~m}^{-2}\right), 3\left(600 \mathrm{~g} \mathrm{~m}^{-2}\right)$ e $4\left(900 \mathrm{~g} \mathrm{~m}^{-2}\right)$, respectivamente. Com maiores doses de cal foram obtidos valores mais elevados de $\mathrm{pH}$ durante os 12 dias do período experimental. Tal resposta afeta diretamente a microbiota da cama, inclusive as Salmonellas spp., tendo em vista que com $\mathrm{pH}$ acima de 9,5 estas apresentam dificuldade de sobrevivência (McWARD \& TAYLOR, 2000; FERREIRA et al., 2004).

Conforme pode ser observado na figura 1,0 número de UFC de Salmonella spp. e Clostridium spp. foi reduzido 82 e $97 \%$ com a aplicação de cal na dosagem de $300 \mathrm{~g} \mathrm{~m}^{-2}$, enquanto que foi observada uma redução de $100 \%$ com a dosagem de 600 e $900 \mathrm{~g} \mathrm{~m}^{-2}$, ambos diferindo significativamente em relação ao controle (antes da aplicação da cal). No tratamento controle, em que não foi aplicada a cal, não foram encontradas diferenças significativas nos diferentes períodos de 


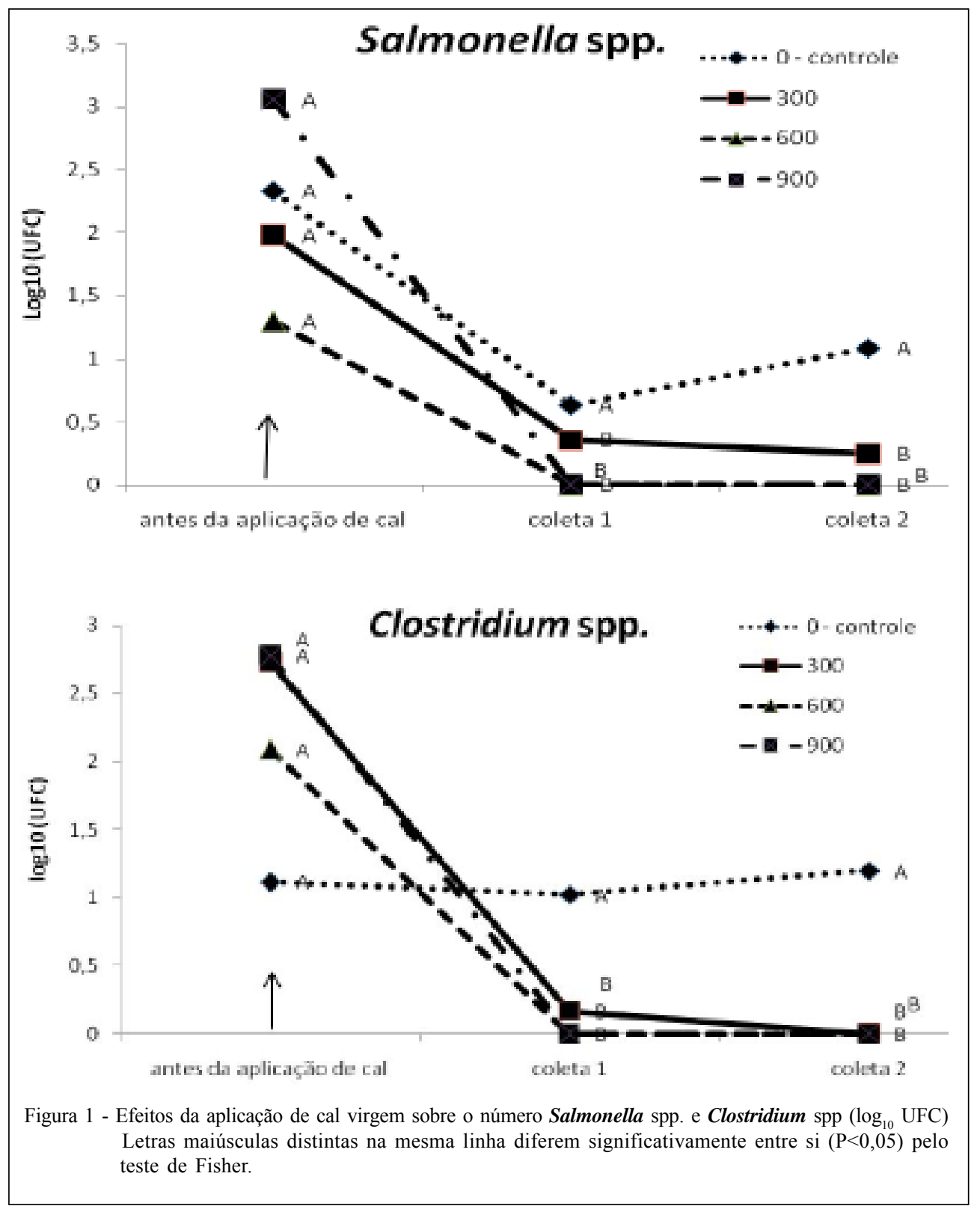

coleta, o que significa que a cama não tratada permaneceu contaminada durante todo o período experimental.

Desse modo, os tratamentos a partir de $300 \mathrm{~g}$ $\mathrm{m}^{-2}$ de cal seriam eficientes para o controle das Salmonella spp. e Clostridium spp., pois a cal eleva o $\mathrm{pH}$, tornando o meio inóspito para as bactérias, além de agir reduzindo a quantidade de água livre e diminuindo a atividade de água da cama de aviário (FERREIRA et al., 2004), sendo esse efeito comprovado neste estudo conforme pode ser observado na tabela 1. Outro produto utilizado com a finalidade de controlar Salmonelas é o dióxido de cloro, o qual tem demonstrado um efeito satisfatório (FERNANDES \& FURLANETO, 2004). Durante o processo de alcalinização, os íons $\mathrm{OH}^{-}$saponificam os lipídios que envolvem externamente, tanto as bactérias, quanto os vírus envelopados, conduzindo a destruição das estruturas de superfície. Em pH superiores a 10, ocorre uma desorganização na estrutura do peptidoglicano bacteriano, hidrólise dos nucleotídeos no genoma vírico e, quando o $\mathrm{pH}$ for superior a 12, ocorre atuação também nas micobactérias (RODRÍGUEZ \& ELIAS, 1999). Desse modo, no presente estudo, os tratamentos que receberam cal seriam eficientes no controle de bactérias e vírus, porém, para o controle de 
Tabela 1 - Atividade de água na cama de aviário antes e após a aplicação de cal.

\begin{tabular}{|c|c|c|c|c|}
\hline & Antes & Após & Diferença (Redução) & Probabilidade \\
\hline $\mathrm{T} 1-0 \mathrm{~g} \mathrm{~m}^{-2}$ & $0,885 \pm 0,011$ & $0,883 \pm 0,009$ & $0,0013(0,2 \%)$ & 0,574 \\
\hline $\mathrm{T} 2-300 \mathrm{~g} \mathrm{~m}^{-2}$ & $0,908 \pm 0,012$ & $0,883 \pm 0,014$ & $0,0257(2,75 \%)$ & 0,009 \\
\hline $\mathrm{T} 3-600 \mathrm{~g} \mathrm{~m}^{-2}$ & $0,905 \pm 0,015$ & $0,879 \pm 0,017$ & $0,0258(2,87 \%)$ & 0,000 \\
\hline $\mathrm{T} 4-900 \mathrm{~g} \mathrm{~m}^{-2}$ & $0,889 \pm 0,017$ & $0,855 \pm 0,018$ & $0,0343(3,82 \%)$ & 0,001 \\
\hline
\end{tabular}

microbactérias, somente os tratamentos que receberam 600 e $900 \mathrm{~g}$ de cal $\mathrm{m}^{-2}$ apresentariam eficiência.

Os valores de $\mathrm{pH}$ dos tratamentos 2,3 e 4 foram elevados. Esse resultado, associado à redução na atividade de água, pode explicar a reduzida recuperação de Salmonella spp. e Clostridium spp. nas amostras.

Observa-se na tabela 1 que a adição de cal reduz a atividade de água na cama de aviário. A partir da dose de $300 \mathrm{~g} \mathrm{~m}^{-2}$ de cal houve uma redução significativa de $2,75 \%$ na atividade de água $(\mathrm{P}=0,009)$. A maior taxa de redução $(3,8 \%)$ foi observada com a aplicação de cal na dosagem de $900 \mathrm{~g} \mathrm{~m}^{-2}$ de cama. A atividade de água influi diretamente na sobrevivência de microrganismos. Com menor disponibilidade de água, o microrganismo necessitará de maior energia para retirá-la da cama, de forma a utilizá-la no seu metabolismo, dificultando ou impedindo sua sobrevivência (HILLS et al., 1997). Por outro lado, sabese que a água livre constitui um meio que possibilita a reprodução, transferência e contaminação microbiológica por Salmonella spp. (RICHARDS \& BEUCHAT, 2005). Porém, na literatura são encontradas apenas sugestões de que a cal diminui a atividade de água na cama (FERNANDES \& FURLANETO, 2004).

Observou-se, também, que as diferentes doses de cal não afetaram significativamente a temperatura da cama, que variou de 28,1 até $28,4^{\circ} \mathrm{C}$. Foi observada apenas uma elevação momentânea da temperatura da cama, em todos os tratamentos com cal, sendo atribuída à reação do óxido de cálcio com os componentes da cama (KWAK et al., 2005), com uma duração média de duas horas após a aplicação (dados não apresentados).

\section{CONCLUSÃO}

Nas condições em que o presente experimento foi realizado, pode-se concluir que a utilização de cal virgem é efetiva na redução de Salmonella spp. e Clostridium spp a partir da dose de $300 \mathrm{~g} \mathrm{~m}^{-2}$ de cama de aviário.

\section{REFERÊNCIAS}

AVILA, V.S. et al. Cama de aviário: materiais, reutilização, uso como alimento e fertilizante. Concórdia, Brasil: EMBRAPA-CNPSA, 1992. 90p.

CORRÊA, É.K. et al. Condicionamento ambiental e desempenho de suínos em crescimento e terminação criados sobre piso com leito de cama. Revista Brasileira de Zootecnia-Brazilian Journal of Animal Science, v.29, p.2072-2079, 2000.

CORRIER, D.E. et al. Effect of used litter from floor pens of adult broilers on salmonella colonization of broiler chicks. Avian Diseases, v.36, p.897-902, 1992.

CHERNAKI-LEFFER. A.M. et al. Isolamento de Enterobactérias em Alphitobius Diaperinus e na cama de aviários no oeste do Estado do Paraná, Brasil. Revista Brasileira de Ciência Avícola, v.4, p.243-247, 2002. Disponível em: http://www.scielo.br/ s c i e lo.php? s cript $=$ sci arttext\&pid $=$ S 1516 $635 X 2002000300009 \& \operatorname{lng}=\mathrm{en} \& \bar{n}^{-}$m=iso\&tlng=pt. Doi: 10.1590 / S1516-635X2002000300009.

FERNANDES, F.C.; FURLANETO, A. Riscos biológicos em aviários. Revista Brasileira de Medicina do Trabalho, v.2, p.140-152, 2004.

FERREIRA, H.A. et al. Efeito de condicionadores químicos na cama de frango sobre o desempenho de frangos de corte. Arquivos Brasileiros de Medicina Veterinária e Zootecnia, v.56, p.542-546, 2004.

HILLS, P. et al. Water availability and the survival of Salmonella typhimurium in porous systems. International Journal of Food Microbiology, v.36, p.187-198, 1997.

KWAK W.S. et al. Effect of processing time on enteric bacteria survival and on temperature and chemical composition of broiler poultry litter processed by two methods. Bioresource Technology, v.9, p.1529-1536, 2005. Disponível em: http:// w w w. $\mathrm{s}$ c i e $\mathrm{n}$ c e d i $\mathrm{r}$ e $\mathrm{c}$ t. science? ob=ArticleURL\& udi=B6V24-4FGXS4V$6 \&$ \& s e r $=687358 \&$ r d o c $=1 \&$ f f t $=\&$ \&_orig $=\mathrm{s}$ e a r c h \& s or t $=\mathrm{d} \& \mathrm{v}$ i e $\mathrm{w}=\mathrm{c} \&$ a c c t $=\mathrm{C} 00000$

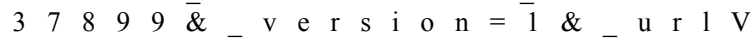
ersion $=0 \&$ userid $=6 \overline{87} 358 \& \mathrm{md} 5=91 \mathrm{f} 47 \mathrm{f} 2 \mathrm{a} 2 \mathrm{cccb} 1 \mathrm{f} 281 \mathrm{~cd} \overline{\mathrm{e}} \mathrm{e} 9 \mathrm{aac} 392239$ Doi: $10 . \overline{1016 / j}$.biortech.2004.12.018.

Mc WARD, G.W.; TAYLOR D.R. Acidified clay litter amendment. Journal Applied Poultry Research, v.9, p.518529,2000

MOORE, P.A. et al. Evaluation of chemical amendments to reduce ammonia volatilization from poultry litter. Poultry Science, v.75, p.315-320, 1996. 
NASCIMENTO, V.P.; SANTOS, L.R. Salmonella enteretidis: controle, implicações em saúde pública e na qualidade dos produtos de origem avícola. In: SIMPÓSIO BRASIL SUL DE AVICUlturA, 6., 2005, Chapecó Anais... Chapecó, SC: Núcleo Oeste de Médicos Veterinários, 2005. p.46-57.

OLIVEIRA, M.C. et al. Teor de matéria seca, pH e amônia volatilizada da cama de frango tratada ou não com diferentes aditivos. Revista Brasileira de Zootecnia, v.32, p.824$829,2003$.

PARDI, M.C. et al. Água - atividade de água. In: CEGRAFUFG. Ciência, higiene e tecnologia da carne. 2.ed. Goiânia: UFG, 2001. p.70

POPE, M.; CHERRY, T.E. Evaluation of the presence of pathogens on broilers raised on poultry litter treatment ${ }^{\circledR}$-treated litter. Poultry Science, v.79, p.1351-1355, 2000.

PROCHONOW, L.I. et al. Controle da volatilização de amônia em compostagem, mediante adição de gesso agrícola e superfosfato com diferentes níveis de acidez residual. Revista Brasileira de Ciência do Solo, v.25, p.65-70, 2001.
RICHARDS G.M.; BEUCHAT L.R. Metabiotic associations of molds and Salmonella Poona on intact and wounded cantaloupe rind. International Journal of Food Microbiology, v.97, p.327-339, 2005. Disponível em: http://www.sciencedirect.com/ science?_ob=ArticleURL\&_udi=B6T7K-4D5KSH6$1 \&$ _user $=\overline{6} 87358 \&$ \&doc $=1 \&$ fmt $=$ \&_orig $=$ search\&_sort $=$ $\mathrm{d} \& \mathrm{v}$ i e w $=\mathrm{c} \&$ a c c t $=\mathrm{C} 000037899 \&$ version $=1 \&$ u r l V e r s i o n $=0 \&$ u s e r $\overline{\mathrm{i}} \mathrm{d}=687$ 358\&md5 $=8050 \mathrm{f} 9 \mathrm{bd} 2426 \mathrm{f978c} 13979612 \overline{5}$ b587a2. Doi: $10.1016 /$ j.ijfoodmicro.2004.05.002.

RODRÍGUEZ F.; ELÍAS F. La desinfección como práctica útil en los programas de lucha contra las infecciones de animales. Anales de la Real Academia de Ciencias Veterinarias, v.6, n.1, p.141-146, 1999.

SINGH, H.P. et al. Effect of different methods of treatment of used litter on growth, feed efficiency and economies in broiler production. Indian Journal Production and Management, v.6, 109-114, 1990.

TEDESCO, M.J. et al. Análise de solo, planta e outros materiais. Porto Alegre: UFRGS, 1995. 174p. (Boletim Técnico, n.5). 